\title{
La responsabilidad en el Código Penal Peruano
}

\section{HUGO PIAGgIO}

A pesar de los defectos que pueden apreciarse en el vigente Código Civil su promulgación constituyó un acontecimiento que hará época en el desarrollo de nuestro derecho y su benéfico influjo se dejará sentir por largo tiempo en la vida jurídica del pueblo peruano.

Pero publicado el nuevo Código Civil y estando muy próxima al parecer la renovación de los Códigos de Procedimientos Civiles y de Comercio, vale la pena que se coloque al lado de éstos cuerpos de leyes, un Código Penal digno de ellos y que responda a las exigencias de los ac. tuales tiempos.

Es muy probable que a muchos les parezca extraño que hable de Ia reforma de nuestro Código Penal, cuya vida no alcanza a veinte años, sobre todo, si se tiene en cuenta, no sólo los elogios que ha merecido de algunos conferencistas extranjeros y del propio presidente de la Corte Suprema, sino también los trastornos que trae el frecuente cambio de la legislación, que es en si mismo un grave mal, ya que sólo son eficaces las leyes que han logrado infiltrarse en la conciencia jurídica del pueblo.

No obstante ésto la necesidad de revisar el actual derecho penal en el Perú, si bien no es unánimemente reconocida, comienza a notarse y exigirse por los jurisconsultos, que encuentran que no es bastante eficaz para detener el avance de la criminalidad, y que, si bien, quizás, está a tono con algunas teorías penales bastante discutibles, sus disposiciones no se inspiran en la realidad nacional.

$Y$ no puede atribuirse el aumento de la criminalidad únicamente a la situación económica reinante, puesto que, realmente no se observa en nuestro país, ningún síntoma de grave penuria social, y si bien, las estadísticas demuestran que los delitos contra la propiedad tienden a auméntar, este aumento no es comparable al que puede notarse en los delitos contra el honor sexual, la familia, el aborto, y el adulterio, que se han multiplicado notablemente.

Injusto sería evidentemente atribuír este resultado exclusivamente - nuestro derecho penal, pero por lo menos basta para asegurar que gracias a sus lagunas y deficiencias contribuye de un modo preponderante al mismo. 
Y ello es explicable, pues, no es un secreto para nadie, que nuestro c. Penal se formó con demasiada precipitación, tomándose como base los proyectos suizos, el Código Holandés de 1912 y el C. Penal Argentino de 1921, a tal punto que en lo esencial puede considerarse como una copia de ellos.

A esto hay que agregar que nuevas circunstancias sociales y económicas han creado también exigencias completamente nuevas en el derecho penal, que han motivado la dación de numerosas leyes especiales, que en lugar de remediar sus deficiencias han hecho oscura e imprecisa su aplica. ción, por su defectuosa redacción unas veces $\mathrm{y}$ otras, por su distinto criterio técnico.

Reafirma la necesidad de reformar nuestro C. P. el notorio quebranto de la fé en la justicia que se observa en la mayoría de los ciudada. nos y aún entre los abogados, agravada por la discrepancia de opinión entre los maestros de la ciencia penal y la lucha entre las escuelas que se hace cada día más aguda.

Ello se debe por una parte a la multiplicación del número de las escuelas, sistemas y teorías, con el consiguiente aumento de confusión; y, por otra parte, en haber traído ciencias no jurídicas, al cuadro del derecho penal, numerosos y heterogéneos problemas ajenos al derecho.

$* * *$

La Corte Suprema que es, sin duda alguna, el órgano más auto. rizado para opinar en estos asuntos ha expresado en cuatro oportunidades consecutivas su opinión francamente desfavorable al C. P. de 1924.

En la Memoria de 1923 decía el Presidente de aquel Alto Tribunal de Justicia:

"Las proyectadas reformas de nuestra ley penal no han tenido el buen éxito que se esperaba. El proyecto de C. P. formulado desde 1916 se ha promulgado el 28 de Julio y rige desde el día siguiente; por fatalidad el C. Penal que se manda promulgar tan precipitadamente, contiene todos los defectos del primitivo proyecto".

"Lo primero que se advierte es la confusión constante que hace el C. P. entre la intervención y las atribuciones de los jueces y de los Tribunales de Justicia, concediendo frecuentemente a aquellos facultades que ya no pueden ejercer según el nuevo $C$. de P. en M. C.".

"Defecto de poca trascendencia, pero que conviene también enmendar es el que se refiere a muchos preceptos de carácter puramente reglamentario que no son propios de un C. Penal".

"Todo el título de la delincuencia de los menores de 18 años está fundado en una doctrina exagerada y peligrosa, que lejos de producir la reforma de los delincuentes puede conducir a su impunidad".

En la Memoria de 1924 el Presidente de la Corte Suprema Dr. Washburn se ocupó también del C. Penal anotando numerosas deficiencias.

En 1925, el catedrático de la Universidad Mayor de San Marcos Dr. Alzamora hizo una crítica acerva de este mismo cuerpo de leyes, poco tiempo después que el Dr. Anselmo Barreto formulara la más completa crítica del C. P. que existe, haciendo notar las numerosas antinomías por él apuntadas que reclamaban un serio trabajo de concordancia, con la 
Constitución (1920) con los C. de C.; de"P. en M.C.; la Ley Orgánica del Poder Judicial; la Ley del Registro de la Propiedad y otras leyes secun darias.

Estas antonomías, tan certeramente anotadas por el Dr. Anselmo Barreto, han aumentado considerablemente, con la publicación de la nueva ley de Quiebras, la ley 9014, la llamada ley de emergencia y e! reciente $C$. de $P$. en $M$. C.

El Dr. Angel Gustavo Cornejo decía en 1928: "El C. P. de 1924, no obstante haber recibido elogios de toda clase, es una obra que no puede perdurar. En 1916 cuando el Dr. Víctor Maúrtua emprendiera la obra por mil títulos laudable, de renovar el caduco edificio de nuestras instituciones penales, existía una profunda desorientación en esta materia. La ardorosa contienda de las distintas escuelas criminalistas había separado a los cultores de esta ciencia en bandos de antagonismo irreconciliable. Los proyectos de codificación de esta época tienen el carácter, antes que de cuerpos legislativos encaminados a solucionar el problema de la defensa social en determinado estado, el significado de ponencias de escuela o programas de cátedra, mirando más a finalidades ideológicas que a la solución dentro de la realidad de los problemas que cada nación tiene que resolver para cumplir la misión de tutelar el derecho y los intereses colec. tivos contra la creciente acometividad de la delincuencia".

Es en esta época de aguda lucha entre las corrientes penales con temporáneas, que el Dr. Víctor M. Maúrtua elaboró su proyecto de C." P. en el Perú y en el cual puede observarse la fuerte influencia que sobre él ejercieron las ramas de la escuela positiva que fundaran Enrico Ferri en Italia y Von Liszt en Alemania.

A este período corresponden los frustrados proyectos noruego de Thyren, los suizos de Stoos (1908_1918), los alemanes (1908_-19lI1919) y los proyectos austriacos.

Ninguno de ellos logró convertirse en ley.

Si el nuestro mereció sanción legislativa, fué porque si bien debe considexársele como un C. Penal afiliado a la escuela positiva, el eclecticismo que adopta en alguna de sus disposiciones le dan cierta originalidad.

Ello puede notarse en los artículos 81 y 83, el primero de los cuales, siguiendo a la escuela clásica, establece como .fundamento de la pena la responsabilidad moral, mientras que el segundo parece fundarila en el postulado positivista de la responsabilidad legal.

La contradicción anotada es de vital importancia, pues, mientras los clásicos cuya doctrina se funda è la responsabilidad moral, construyen su sistema penal sobre los conceptos de libre albedrío, los positivistas lo niegan y colocan como piedra angular de todo su sistema a la responsabilidad legal.

Estamos, pues, en presencia de dos direcciones opuestas de medio a medio. ¿Por cuál de ellas debemos decidirnos si se llega a reformar nuestro C.P.?

Seuffert:

En un folleto publicado en Alemania opinaba el Profesor $\mathrm{H}$.

"Por fortuna nosotros no metemos la disputa acerca del libre albedrío entre a las que a la ciencia penal se refieren, la remitimos a la teología y 
a la filosofía, estudiamos únicamente con ahinco los hechos averiguados por la experiencia".

Pero ces que el libre albedrio no es un hecho también averiguado por la experiencia? ¿Y no deberá un jurista formarse ideas claras acerca de la culpa, la responsabilidad y la imputabilidad, acerca del fin y la significación de la pena?

Salta a la vista que cualquiera de estos conceptos cambia radicalmente según que se admita o rechace el libre albedrío. Basta para ello leer a Enrico Ferri o Franz Von Lizst para convencerse que todos los concep. tos fundamentales de esta ciencia resultan tergiversados en la concepción determinista.

El propio Franz Von Lizst reconoció, en un artículo publicado en la Revista Mensual de Sicología Criminal, que desde hace miles de años la humanidad ha caminado inseparablemente unida con los conceptos de libertad moral, libre albedrío, culpa, y que el determinismo científico no ha logrado ejercer gran influencia en la cultura jurídica de los pueblos.

Este problema no ofrece dificultad alguna para los católicos. La Iglesia lo ha resuelto: El Concilio de Trento excomulgó a los que afirman que la voluntad se perdió por el pecado original.

La doctrina de la Iglesia está también contenida en las Sagradas Escrituras, de modo que debe ser firmemente creída por todos los fieles cristianos.

Pero, por muy valioso que sea el testimonio de la revelación cris. tiana en pro de la existencia del libre albedrío, vale muy poco o nada para la mayor parte de los tratadistas positivistas de derecho penal, motivo por el cual, nos vemos obligados a recurrir a la razón, ante la cual inclinan su frente cristianos y no cristianos.

Nuestra conciencia nos atestigua que somos libres en todos nuestros actos, que no los ejecutamos porque nos vemos forzados a ellos, sino porque libremente asi lo queremos.

En general el testimonio de la conciencia es admitido hasta por los propios deterministas. quienes pretenden esquivar su fuerza demostrativa, diciendo que es sencillamente una ilusión.

Así por ei. dice A. Forel: La ilusión del libre albedrío descansa únicamente sobre el desconocimiento de los motivos de nuestras acciones. En términos parecidos se expresan Enrico Ferri, Von Hippel y otros muchos que siguen a Spinoza.

Pero si toda certeza presupone la seguridad en lo que claramente nos atestigua la conciencia i no equivale a negar toda certeza declarar una ilusión la clara conciencia de nuestra voluntad?

Con razón escribe Wundt: "Lo que toda conciencia normal, presupuesto el suficiente conocimiento, reconoce como inmediatamente evidente lo llamamos cierto".

También se ha recurrido a los fenómenos del hipnotismo para quitarle toda su fuerza demostrativa de la libertad. Pero cualquier argumentación que se base en ello, carece de todo fundamento porque no son comparables los fenómenos extraordinarios de hombres enfermizos y anormales a los fenómenos de los hothbres normales.

Sentar el principio contrario, es admitir que todos los hombres es. tán hipnotizados. 
Las manifestaciones de nuestra conciencia nos atestiguan psi mismo la existencía del libre albedrío.

El delincuente que acecha traidoramente a su víctima oye distintamente el grito de su conciencia que le dice: ¡No mates! ¡No robes!

Von Hippel pretende que no siendo la conciencia más que la suma de las exigencias éticas de nuestro carácter, el déterminismo puede explicar satisfactoriamente el grito de la conciencia.

La afirmación de Von Hippel es errónea porque, si la conciencia no es otra cosa que la suma de nuestras costumbres o exigencias ticas, nos sentiríamos siempre inclinados a realizar los actos conforme a nuestro temperamento.

Pero la realidad es otra, pues las exigencias de nuestro carácter nos impiden dejarnos llevar por nuestras inclinaciones.

Los que se empeñan en harer past: las acciones humanas romo re. sultado necesario del carácter o de la personalidad toda entera del agente, no pueden en modo alguno explicar el hecho tan frecuente en la histora de los santos que de repente cambian por complets de ri:odo de vivir.

¿Por qué San Pablo o San Agustín no siguieron siempre en el mismo tenor de vida?

Todos los esfuerzos destinados a demostrar que el hombre no es libre, se estrellan contra la sana filosofía que tiene abundahtes pruebas para demostrar lo contrario.

En el art. 81 nuestro C. P. define el problema de la imputabilidad aceptando la causalidad moral, o sea, que el delito es el fruto de la activi. dad consciente del hombre y no una simple reacción automática como pretenden los positivistas.

La declaración que contiene el art. 81 está completamente de acuerdo con la conciencia colectiva y la opinión pública del Perú, que en todo tiempo consideró necesario vincular la imposición de la pena a la calidad moral de las acciones.

$Y$ a pesar de la fuerte influencia positivista que se deja sentir en todo el articulado del C. P. sus autores se vieron obligados a acoger la causalidad moral, porque, como dijera Enrico Ferri comentando el vigente C. P. Italiano elaborado por Rocco: "Cuando me encuentro en mi Gabinete de trabajo puedo dejar que mi pensamiento vuele libremente a los horizontes más lejanos y aparentemente más irrealizables, pero cuando uno debe realizar obra legislativa, debe tener en cuenta, ante todo, las condiciones reales del pueblo y los estados de la conciencia y del sentimiento público para los que se dan las leyes... Los hombres de Gobierno deben contemplar estos problemas desde otro plano, porque la función de la ciencia y la función legislativa son incompatibles".

La aceptación del libre albedrío en el art. 81 obedeció a la necesidad de acoger el común sentir de la nacionalidad, que desde tiempos muy remotos admite que sin libertad no hay imputabilidad moral y que sin imputabilidad jurídica no hay derecho penal posible.

$Y$ este triple anillo de defensas encierra todo el campo del derecho penal. 
Es por ello que el positivismo que no admite la libertad, que suprime el concepto de la imputabilidad reemplazándolo por el de la peligrosidad social, no permite más fundamento a la pena que el de la defensa social, que se ejercita contra el hombre de la misma manera que contra cual. quier peligro natural.

Sin embargo, las legislaciones penales y las doctrinas de la segunda mitad del siglo XIX pretendieron construir la teoría de la imputabilidad sin tomar en cuenta el principio de la libertad, declarándose contrarias a tomar posición en el debate filosófico o agnóstico sobre esta materia.

Ejemplo de ello es el Código Penal Italiano derogado cuyo autor Zanardelli, decía: "Yo admito la libertad de elección, porque es la nota característica de la libertad y dignidad humana, pero creo justa la observación de Kant, que no puede levantarse un cuerpo de leyes sobre una base filosófica discutida".

Igual punto de vista puede observarse en el actual C. P. Italiano, que si bien pretende conservar la causalidad moral y cierra las puertas a la responsabilidad social, no ha sabido ir más allá de la fórmula del C. P. derogado.

Pero si nuestro Código Penal supera a los cuerpos de leyes antes mencionados por su admisión sin ambajes de la causalidad moral en el art. 81, incurre en el gravísimo error de admitir la responsabilidad legal en el art. 83, que prescribe la represión del agente de la infracción no intencional ni culposa en los casos de peligro social.

No creemos necesario insistir sobre esta contradicción que hace difícil la interpretación de nuestra ley penal porque ha traído hasta ella el debate de las escuelas penales en lugar de superarlas. 